Macy, I. G. (1 949). Amer. F. Dis. Child. 78, 589.

Macy, I. G., Hunscher, H. A., McCosh, S. S. \& Nims, B. (r930). F. biol. Chem. 86, 59.

Mellander, O. (1945). Nature, Lond., 155, 604.

Nelson, W. E. (1950). Mitchell-Nelson Text-book of Pediatrics, 5th ed. Philadelphia and London: W. B. Saunders Co.

Nims, B., Macy, I. G., Hunscher, H. A. \& Brown, M. (1932). Amer. F. Dis. Child. 43, 1062.

Planchu, E. \& Rendu, R. (191 1). Arch. Méd. Enf. 14, 582.

Polskin, L. J., Kramer, B. \& Sobel, A. E. (1945). F. Nutrit. 30, 45 I.

Ružicić, U. S. (1934). Mschr. Kinderheilk. 60, 172.

Williamson, M. B. (r944). F. biol. Chem. 156, 47 .

\title{
Artificial Infant Feeding
}

\section{By J. N. Smellie, Department of Paediatrics and Child Health, University of Birmingham}

It can be accepted as axiomatic at the present time that the basic food substance for the artificial feeding of healthy infants is cow's milk. In the first place, therefore, attention must be directed towards a comparison between human breast milk and cow's milk. Ideally, the substitute food should approximate to nature's food as closely and as exactly as possible. Towards the end of the last century this seemed to be a simple and relatively easy procedure and was the basis of what was called the percentage method of infant feeding. The protein, fat and carbohydrate content of the two milks was known and a little juggling with cow's milk, sugar and water provided the satisfactory modification. The advances of science and chemical analysis soon revealed differences, particularly in the proteins and fats of the two milks, and then the different amino-acid composition and the varying amounts and proportions of the many mineral substances began to render the problem increasingly difficult and complex. To-day, a perusal of current paediatric text-books and handbooks on the artificial feeding of healthy infants and a cursory glance at the spate of pamphlets, booklets and advertisements of the manufacturers of infant feeds leaves one disconcerted, overawed and aghast. Not unnaturally, the impression is being created, particularly in the minds of the uninitiated, that the whole subject is confused and chaotic. Indeed, the position might almost appear to be that, before any intelligent advice can be given on substitute or bottle-feeding, technical knowledge of the chemical composition of the innumerable constituents of breast and cow's milk must be profound, precise and exact. Surely this pseudo-scientific approach has been overdone, and has not the time come when we should return to a more simple, commonsense and realistic attitude?

It is submitted that fundamental principles seem to have been buried beneath a welter of secondary, minute or perhaps even unessential details. To-day in the streets of our cities and towns we can see countless happy, healthy and contented babies reared on artificial feeds by parents with a very wide range of intelligence, and it is difficult to feel that all have followed current professional advice, assuming that this has been sought. Let me reiterate that I am only concerned with the feeding of healthy infants; the problems in connexion with sick or premature infants will be dealt with by other speakers. 
The principles to be observed are not really very complicated, and differ quantitatively but not qualitatively from those involved in meeting the nutritional requirements of any mammal, man or otherwise, with due allowance for the factors of growth and development. Human beings, for at least their first 6 months of life, are carnivora.

\section{Nutritive values of cow's and human milk}

In the first place, brief reference will be made to some of the known facts concerning the nutritive value of cow's milk in comparison to breast milk, as well as to some of the gaps in our knowledge. Such an approach is an essential pre-requisite for a proper appreciation of the problem of artificial feeding of all babies.

Protein. As a healthy infant has to double its birth weight in 6 months and treble it by its first birthday its protein intake must be of major importance. Cow's milk has more than twice the protein content of breast milk. During the first 6 months of life, infants fed on undiluted cow's milk show a steady increase in percentage of body nitrogen. This is in contradistinction to those breast-fed, who do not quite maintain their birth percentage of nitrogen (Stearns, 1939). Since, therefore, the body of the infant fed on cow's milk contains a greater percentage of nitrogen, the amount of intracellular fluid and salts must also be greater. The potassium retention in an artificially fed infant is considerably above that of a breast-fed infant and the same may be assumed to be true of sodium and phosphorus. Why this is so and what influence it may or may not have is not yet known; presumably it is in some way associated with the greater amount of protein in cow's milk and the different aminoacid pattern of the two milks. Williamson (1944) has compared breast milk with half-strength cow's milk and found that the former contained over three times as much cystine as the latter. There was less methionine in human milk, but no significant differences in the total sulphur-containing amino-acids. The stools of infants artificially fed when compared to those breast-fed have been shown (Ross, 1950) to contain very few amino-acids as determined by partition chromatography, and the chromatographic pattern was not constant. The higher protein content of cow's milk may, in part at least, explain these differences. Further investigations, however, on these lines (Ross, 195I) suggest that the protein of human milk is almost completely metabolized, and the absorption of food is so efficient that the faeces of the breast-fed baby contain only amino-acids provided by the intestinal flora and intestinal secretions. The significance of these findings has yet to be assessed.

Fat. The total fat content of the two milks is not dissimilar, but the acids of human milk differ from those of cow's milk in that they do not contain butyric or other lower acids. Indeed, human milk, in regard to its component acids, has more resemblance to a typical margarine-fat blend than to butterfat (Hilditch \& Meara, 1944).

Minerals. There are significant differences in the mineral contents of the two milks, but these are subject to wide variations depending on the diet. On average, breast milk contains only about one-quarter the calcium of cow's milk, but there is a much greater percentage absorption of the former, probably due to the different bacterial content and hydrogen-ion concentration of the intestine of the breast-fed 
baby associated with the higher lactose content. The amount of iron present in human milk is about three times that of cow's milk and an iron-deficiency anaemia develops in artificially fed infants unless additional iron is prescribed.

Vitamins. In general, breast milk contains more vitamins $\mathrm{A}$ and $\mathrm{C}$ but less vitamin $B_{1}$ and riboflavin than cow's milk; vitamin D is inadequate in both (Kon \& Mawson, 1950). Scurvy is very rare in breast-fed infants, probably because the diet of most nursing mothers contains adequate amounts of vitamin $C$. It would seem that breastfed infants need only small amounts of vitamin $B_{1}$ in contradistinction to those that are bottle fed, but little is known concerning their riboflavin requirements.

Calories. Most of the calories that an infant expends are derived from the fats and carbohydrates, and there is no significant difference in the calorie values of human and cow's milk.

\section{Nutritive needs of the human infant}

Turning now from the theoretical and more scientific aspects to practical application, it is immediately apparent that the large number of artificial infant-foods available and in use demonstrates in no uncertain manner that these are a long way from being as satisfactory or ideal as human milk. In this connexion the first question that arises is what are the essential nutritive requirements of a healthy growing infant. It is platitudinous to state that the food intake must be adequate; without this, normal growth and development cannot proceed. There is broad agreement on the calorie intake required, namely 50-60 Cal./lb. body-weight/day. With regard to total fluid intake, here again most authorities agree that $2 \frac{1}{2} \mathrm{oz} . / \mathrm{lb}$. body-weight/day may be accepted as the average. Thus, a feed containing $20 \mathrm{Cal} . / \mathrm{oz}$. and given in the proportion of $2 \frac{1}{2} \mathrm{oz}$./lb. body-weight/day will satisfy the fluid and calorie requirements of most healthy babies. Controversy and difficulties, however, arise over the modifications of cow's milk that should be made to meet the above-mentioned criteria. It is universally recognized that whatever fluid is fed to the infant must be sterile, and in the first place, therefore, the cow's milk mixture must be free from all bacteria and micro-organisms. Dried or powdered milks have many practical advantages, and fresh cow's milk should never be used unless it has been boiled or pasteurized. Drying, boiling, pasteurizing or evaporating cow's milk have one common advantage in that they render the casein curd less dense and tough and therefore easier of digestion. In the interests of all concerned simplicity must be our motto, and powdered milks made from unmodified cow's milk have much to commend them; the required feeds are easy to prepare, satisfactory to the baby, very convenient for the mother and can readily be modified to suit the conveniences and idiosyncracies of the individual baby.

\section{Modification of cow's milk for infant feeding}

Protein. Two problems now arise on which professional opinion is far from unanimous. The questions are $(a)$ what modifications are really necessary, and $(b)$ in what quantities and at what intervals should the infant be given its feeds. Our paediatric teachers of a generation ago were rather apprehensive of the relatively 
high protein content of cow's milk and taught that this should be reduced to a level more approximate to that of human milk. 'Protein indigestion' as it was called is now considered a bogey, since we have learned to modify the protein curd before its ingestion. Indeed, in these days it is almost impossible to obtain protein curds in the stools of infants for demonstration to medical students. The paramount importance of an adequate protein intake in both health and disease is now universally recognized, and in this connexion tribute must be paid to the protracted and invaluable investigations and research of our colleagues in the nutritive and metabolic fields. In consequence of these advances in knowledge the high protein content of cow's milk is considered to be very far from a disadvantage, and almost all infants will tolerate, and benefit from, full-protein cow's milk.

Fat. With fat the matter is a little different for reasons already mentioned, hence the demand for half-cream milk mixtures. Fat intolerance is still a clinical entity, as the secretion of lipase in the infant is poor, and if produced the resulting disturbance can be extremely troublesome.

Carbohydrate. Attention has earlier been directed to the fact that an infant derives most of its calories from fat and carbohydrate. If, therefore, fat has to be reduced, a compensatory increase in the amount of carbohydrate is essential. As cow's milk contains less than two-thirds the carbohydrate in human milk, the necessity for additional carbohydrate is clear. Opinions differ on the best form of carbohydrate for this purpose, but personally I favour the readily available commodity, cane-sugar. I have yet to be convinced that glucose, or dextrose-maltose mixtures, which are more expensive and not so palatable, have any advantages.

\section{Amount of feed and interval between feeds}

Until quite recently the amounts in a feed and the intervals between feeds have been rather rigidly defined, but it is becoming more and more appreciated that an infant's desire for food as well as its need are subject to considerable variation from time to time and from day to day. Why should an infant, who through no fault of his own has to be bottle fed, be still further jeopardized by being deprived of satisfying his individual needs and desires like his breast-fed brother? I cannot subscribe to the opinion that $2 \frac{1}{2} \mathrm{oz}$. fluid/lb. body-weight/day is the optimum in all instances and will provide all that an infant needs, or that the quantity of each of the individual feeds should be obtained by dividing the total by the number of feeds. This is a ritual much too rigid and uncompromising and ignores the baby's appetite, preferences and desires. Such a procedure is against all the rules of nature. Amounts in a feed and intervals between feeds should be elastic and flexible, permitting the individual baby to exercise at least a little personal choice and selection. Do let us remember that babies are individuals. Wallgren (1945) has shown from a detailed study of nearly 400 normal breast-fed infants that there is no significant correlation between bodyweight and milk consumption, and that the amount a particular baby may take is unpredictable. In Birmingham for the last year or more we have been using a modified self-regulating feeding schedule for artificially fed babies, with most pleasing results. The baby is offered a feed and allowed to suck until satisfied, but no attempts 
are made to force feeds after his requirements, as judged by disinclination to take more or passing off to sleep, have been met. Detailed charts showing amounts in a feed have been kept for some of these babies over a period of time. The results have been most instructive and fully confirm Wallgren's observations on breast-fed babies.

Though I am not in complete agreement with the views expressed by some that a healthy baby cannot be overfed, experience has taught that underfeeding is a very much more common fault than overfeeding.

\section{REFERENCES}

Hilditch, T. P. \& Meara, M. L. (1944). Biochem. F. 38, 29.

Kon, S. K. \& Mawson, E. H. (1950). Spec. Rep. Ser. med. Res. Coun., Lond., no. 269.

Ross, C. A. C. (1950). Lancet, 258, 716.

Ross, C. A. C. (1951). Lancet, 26r, 190.

Stearns, G. (1939). Physiol. Rev. 19, 415.

Wallgren, A. (1945). Acta. Paediatr., Stockh., 32, 778.

Williamson, M. B. (1944). F. biol. Chem. 156, 47 .

\section{Difficulties of Infant Feeding}

\section{By A. V. Neale, Department of Child Health, University of Bristol}

There is no field of practical infant management of greater importance than that connected with the quick, precise and satisfactory solution of problems concerning alleged or real difficulties in infant feeding. In all spheres of paediatric practice there is a regular flow of such disorders, and each example needs individual consideration in order to find the correct solution. Like many other apparently simple clinical matters, the proper assessment of a feeding difficulty may call for the highest ability, either in detecting an unsuspected minor disturbing influence or in recognizing a potentially serious organic cause. A good understanding of the relationship between mother and infant is necessary as a background; an infant-welfare clinic will usually provide abundant training and experience in the social and psychological factors involved. Perhaps the increasing tendency for a mother to discover a feeding diffculty is a sign of present-day anxieties and, not least, is often a reflexion of sociomedical difficulties in accommodation, adaptation or adjustment, arising out of the housing problems of young parents.

Psychological considerations. Undoubtedly, worries and troubles in the mother's mind are the essential matter in very many instances; they may arise through the sheer lack of common sense of a young, ignorant and somewhat emotionally immature woman, or strangely enough, they may be the reaction of the elderly, knowledgeable mother who is carrying an unusual load of anxiety about her first and possibly last baby. A careful and quietly observant approach must be made by the doctor wishing to discover the whole truth. A mother may be quite reticent over the facts really helpful for understanding her problem as a whole. It is certainly no occasion for hasty and superficial methods. The whole story quietly told and explored is essential. An air of sympathetic understanding of the mother's feelings and sense of responsibility must be revealed, and a genuine wish to understand and help must be shown. 